\title{
EDUCAÇÃO SOMÁTICA COMO ALIADA NO CUIDADO INTEGRAL DE PESSOAS EXPERIENCIANDO DISSIDÊNCIAS SEXUAIS E DE GÊNERO
}

\author{
SOMATIC EDUCATION AS AN ALLY IN THE INTEGRAL (HEALTH AND SOCIAL) \\ CARE OF PEOPLE WHO EXPERIENCING SEXUAL AND GENDER DISSIDENCES
}

\author{
Lidiane de Melo Drapala e Márcia Cristina Baltazar² \\ 1 Universidade Federal de Sergipe, Departamento de Teatro, Brasil, e-mail: drapala lili@hotmail.com, \\ ORCID: https://orcid.org/0000-0002-8009-729x \\ 2 Universidade Federal de Sergipe, Departamento de Teatro, Brasil, e-mail: marciabalta@gmail.com, \\ ORCID: https://orcid.org/0000-0001-5455-1287
}

\author{
ARTICLE INFO \\ Article history: \\ Received 2020-06-01 \\ Accepted 2020-11-30 \\ Available online 2020-11-30
}

Palavras-chave: Educação Somática, Teatro, Dissidência de Gênero, Sexualidade, Saúde Integral.

Keywords: Somatic Education, Theater, Gender dissidences, Sexuality, Health Care.

RESUMO. No período de julho/2017 a julho/2018 foi desenvolvida na Universidade Federal de Sergipe (UFS) campus São Cristóvão a pesquisa PIBIC Voluntária "Pedagogia do Corpo Criador (ou Teatro Somático)"; aqui, detivemo-nos ao recorte da aplicabilidade no campo da saúde. Assim, a aluna do curso de Teatro licenciatura fez pesquisa bibliográfica e discussões temáticas de modo a angariar compreensões acerca da viabilidade do desenvolvimento de Projeto de Educação Somática para pessoas transexuais, travestis, ou ainda, que se entendessem e/ou vivenciassem (n)as "dissidências de gênero". Destaca-se a urgente e necessária crescente visibilização da agenda política pela garantia de direito da população já mencionada. Ainda assim, percebe-se escassez ou frágil sistematização de modos de atenção e cuidado à mesma, bem como a fronteira muito próxima dos estudos de gênero e as inumeráveis discussões acerca da performatividade de gênero enquanto construção social em diálogo constante com o(s) fazer(es) artístico(s). Vislumbrou-se campo fértil para o que nomeou-se ao final do referido ciclo de pesquisa: "Técnica Somática para a Saúde - interfaces da Educação Somática com Técnica Klauss Vianna para questões de Saúde Integral e Cidadania para pessoas Trans". Cumulando reflexões sobre o grande guarda-chuva de técnicas compositoras do campo da educação somática e usando como baliza a Técnica brasileira Klauss Vianna, agruparam-se pistas para o trabalho pedagógico, o manejo terapêutico direto e/ou indireto e a potencialização da autonomia no processo criativo de si mesmas(os).

ABSTRACT. From July/2017 to July/2018, the Volunteer's PIBIC research "Pedagogy of the Creator Body (or Somatic Theater)" was developed at the Federal University of Sergipe (UFS) campus São Cristóvão. Our part in this research was focused in the appliance in the health field. Thus, as a beginner theater student we did a bibliographic research with thematic discussions in order to gain understandings about the viability of the development of the Somatic Education Project for transsexual people, transvestites, or even, who understood and / or experienced (n) the "Gender dissidences". The urgency and necessary growing visibility of the political agenda is highlighted by the guarantee of the right of the population already mentioned. Even so, there is a scarcity or fragile systematization of modes of attention and care to it, as well as the very close frontier of gender studies and the innumerable discussions about gender performance as a social construction in constant dialogue with the doing (s) artistic (s). A fertile field was envisaged for what was named at the end of the aforementioned research cycle: "Somatic Technique for Health - Somatic Education interfaces with Klauss Vianna Technique for issues of Integral Health and Citizenship for Trans people". Cumulating reflections on the great umbrella of composing techniques in the field of somatic education and using the Brazilian Technique Klauss 
Vianna as a guideline, clues for pedagogical work, direct and / or indirect therapeutic management and the enhancement of autonomy in the process were grouped creative of themselves.

Na última década, temos sido chacoalhadas(os) com um turbilhão de provocações acerca de questões sobre gênero suas diversas possibilidades de expressões, as ditas dissidências de gênero bem como sobre sexualidade(s) e suas expressões e orientações. Ou mesmo, a inexistência de fluxo de interesse/desejo sexual, como no caso das pessoas assexuais. São diversas as estratégias de provocação e mobilização social, de agrupamentos e organismos/entidades/coletivos que lutam pelas garantias de direitos Igbtqi $+{ }^{1}$. Dos mais complexos aos mais basilares. Como é o caso do direito à vida propriamente dita.

Entidades tais como o Grupo Gay da Bahia (GGB, do conhecido pesquisador e militante, o antropólogo Luiz Mott), a Rede Trans Brasil, a Rede ANTRA, entre tantas outras vieram escancarar uma grande problemática brasileira. Com a formalização em dados de absurdos assassinatos de pessoas lgbts, e, mais especificamente (para nosso estudo) travestis, transexuais, transgêneros no Brasil, temos uma realidade muito dura a encarar.

Assim, demarcam um indicador social da "expectativa de vida" dessa população trans em nossos tempos. Com a catalogação de recortes de jornais e revistas impressas, com as visitas em delegacias de polícias, elencando informes virtuais em diversas redes e mídias sociais ou mesmo as chamadas "mídias alternativas", chegou-se ao alarmante anúncio: "a vida travesti e/ou transexual não ultrapassaria os $\mathbf{3 5}$ anos". Exemplo desse trabalho é o "Dossiê: A geografia dos corpos das Pessoas Trans" lançado em 2017 em meio virtual pela Rede Trans Brasil.

São assassinatos brutais, com requintes de muita crueldade, suspeitam-se e demonstram-se, inclusive, corpos marcados e trucidados com a produção de diversas técnicas de tortura. É inegável o ato de infringirem muita dor, sofrimento, humilhação social. Algo da ordem das grandes barbáries. Diz-se isso associando mesmo à "história oficial" dos grandes genocídios em nosso planeta.

Tal realidade intriga por várias razões. Iniciamos pela dita inteligência atribuída a nós humanos desenvolvidos em contínuo progresso. Além do cerne moral "do bem" estruturando discursos populares, religiosos, partidários, acadêmicos, e, muito cientificistas.

\footnotetext{
${ }^{1}$ Entendemos por aprendermos com o próprio movimento, que a sigla oficializada pela conferência nacional por seus direitos seria LGBT. Todavia, também percebemos no social as diversas provocações ao mesmo fluxo a sua ampliação, no sentido mesmo de abraçar mais "bandeiras, provocando quase que uma contra-hegemonia na própria militância e ativismo.

2 Aqui registramos a ideia de "Mídia alternativa" para os meios de comunicação que fogem da propriedade das grandes oligarquias políticas que se assenhoraram das "concessões" públicas em diversos formatos.
} 
Aumenta-se sobremaneira o estranhamento quando se ouvem levantamentos, mapeamentos e exercícios de pesquisa denunciando o paradoxal "interesse/desejo" brasileiro em sites da internet com conteúdos pornográficos. Há quem se dedique a testar os tais "trend topics" pornô e, se depare com os itens mais buscados: "sexo com travestis", "sexo com trans" e, por aí em diante.

Registramos aqui o PodCast "Movimento LGBT" realizado em 2017 pelo Centro Acadêmico do curso de Direito da Universidade Federal de Sergipe. Nesse programa, abordaram-se questões acerca das dificuldades no processo da garantia dos direitos das pessoas trans e travestis. E, num dado momento o condutor das entrevistas informou sobre curiosa busca em sites pornográficos. Expôs a constância de uso do produto audiovisual protagonizado por travestis, transexuais, transgêneros como sendo um dos mais buscados nos sites especializados.

Considere-se o meio audiovisual como uma modalidade de registro da experiência num instante. São corpos em destaque, são corpos trans e travestis performando suas expressões de desejo, de gozo, da relação sexual propriamente dita. A primazia da relação visual acionada com esses dispositivos deixando contundentemente marcadas as vidas ali expostas, ainda que num ato forjado para uma dita cena. Ainda assim, como dar conta de tamanhas contradições? Um país que assassina brutalmente um público que ao mesmo tempo Ihe chama a atenção em sua intimidade, sua experimentação libidinal. Como lidar com essas realidades? Seriam elas opostas, complementares, simétricas ou assimétricas por oposição?

Feito todo esse percurso de implicações, surgem outras questões. O que fazer quando se é profissional atuando em questões de saúde, como é no caso da psicologia? E, quando se insere num curso de licenciatura, em artes, lidando com vertentes mais atuais como 'presença ampliada', 'qualidade de presença', 'possibilidades performáticas'?

Jussara Miller em seu "Qual é o corpo que dança?" traz um tópico acerca do "Corpo Presente". E, logo de início, afirma que "constrói-se o corpo presente por diversas estratégias e procedimentos diferenciados cuja premissa é a escuta do corpo" (MILLER, 2012, p. 49). Intriga-nos, diante dessa possibilidade, a assimilação do suposto parodoxo por parte das pessoas trans e travestis. Como seria estar habitando um corpo, estar produzindo um corpo, estar retroalimentando uma presença que ora é super-objetificada, mortificada ou mesmo assassinada; ora é sua bandeira de ativismo para existir, e, talvez por isso mesmo.

A Técnica Klauss Vianna originou-se nos meios artísticos da dança, do teatro, avançou para expressões vocais, musicalidades, espetáculos musicais. Desde sempre abrangeu as questões da saúde e é classificada como as "técnicas somáticas", ou a "educação somática" 
e quiçá, inclusive, se relacionará à noção de "somática (do) social" da estadunidense Jill Green - abordaremos este conceito em pesquisas posteriores.

Voltando à Miller (2012), vê-se toda disponibilidade do universo dos Vianna ${ }^{4}$ em avançar, em se entrecruzar. A autora cita no processo de sistematização da Técnica que "o conhecimento adquirido pelos alunos de áreas tão diversas (para além dos artistas do corpo, grifo nosso) serve como material facilitador da percepção da singularidade e da autenticidade inerente ao trabalho aqui proposto" (p.44). Diz ser premissa fundamental a compreensão do 'corpo em movimento' independente da função, posto que interessa prioritariamente o 'humano' manifestado. E, registra a noção do corpo somático como o elementar no trabalho.

Atualmente, vale destacar, há um movimento macro em vias de sistematizar o guardachuva das técnicas envolvidas na "educação somática". No "9 Seminário Angel Vianna", ocorrido em 2015 na cidade do Rio de Janeiro, dentre os trabalhos apresentados, selecionamos aqui o "Investigando a somática: história, teorias e possíveis caminhos". Guilherme Potério dos Santos Hinz, dançarino e pesquisador inicia com sua pesquisa o esboço de uma possível historiografia da Educação Somática. Interessa-nos sobremaneira o registro e o esmero em agrupar diversas influências e percursos até essa compreensão.

Ao fim do trabalho, arrisca traços cartográficos para a produção de algo como um mapa mental dessas convergências. Como adjetivado, há o cuidado em anunciar o que seria uma prática direta ou uma influência tanto quanto a que área anterior se relacionaria, a saber, artes, somática, psicologia, filosofia, educação.

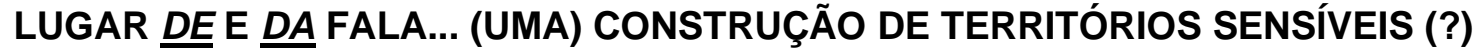

Esta pesquisa toma referências de algumas vivências pessoais das pesquisadoras aqui presentes, relacionando-se, portanto, com um campo híbrido de multirreferências, de afetações, de intersecções. Agrega temas, conceitos e debates da Psicologia e os processos de subjetivação, memórias de seus trabalhos com o Sistema de Garantia de Direitos de

\footnotetext{
${ }^{3}$ A teoria social-somática baseia-se nas ideias de escritores como Don Johnson e Elizabeth Behnke, que abordam questões de autoridade corporal e demonstram como nossos corpos são moldados pelas culturas em que vivemos. A partir dessa perspectiva, a cultura ocidental cria o mito de uma separação corpo/mente. No entanto, esta separação não divide simplesmente as nossas mentes dos nossos corpos e favorece a mente em detrimento do corpo. Em vez disso, há uma obsessão ativa com o corpo como uma entidade objetiva e mecânica. Há um foco no corpo, mas como um instrumento mecânico e não como um soma. Através de uma normalização sobre como os corpos deveriam ser e agir, a cultura dominante mantém o controle à medida que as pessoas abandonam sua autoridade corporal. Deveríamos dizer que essa teoria pode ser usada de maneira afirmativa, à medida que as pessoas são capazes de um maior agenciamento, pois o corpo é usado como resistência às normas culturais (GREEN, 2019, nota 3, p. 28).

${ }^{4}$ A Técnica Klauss Vianna (MILLER, 2012) é uma prática de estudo de consciência corporal para a arte do corpo e educação somática desenvolvida entre diversos artistas pesquisadores que aprofundaram, em várias vertentes, as pesquisas inovadoras de Klauss Vianna, Angel Vianna, Rainer Vianna e Neide Neves.
} 
grupos vulnerabilizados, pesquisas em políticas públicas artísticas, educacionais, de saúde entre outras; além das mais recentes inquietações pelas questões de gênero, pelos direitos Igbtqia+, inclusive trazendo as relações de uma das pesquisadoras em um percursos com atendimento a pessoas trans num projeto-piloto de ambulatório de saúde integral na modalidade portas abertas.

Ressaltam-se ainda algumas experimentações no campo das artes com vivências em teatro experimental com inspiração no teatro do absurdo, no teatro da vertigem. O encontro das duas também reconheceu interesses comuns no qua tange a questões político-afetivas do ser no mundo, expansão das corporeidades por reflexões filosóficas como as da diferença, com linguagens mais pós-modernas culminando nessa experiência de orientação/supervisão em um programa oficial de pesquisa além da abertura de novos horizontes perceptuais no campo da expressão corporal pelo viés da educação somática.

Portanto, habitando a cidade, se afetando com seus caminhos, se atravessando por existências vívidas do que move o cenário político do seu país, do seu território, não haveria como passarem ilesas por esse caos criativo e provocativo. Permitindo-se a fruição com o escrito de Maíra Gerstner também para o "9 Seminário Angel Vianna" em "O corpo como território do sensível - aproximações entre arte, educação e clínica" (2015). Aponta que, "mais do que arte-terapia, o caminho da arte para a clínica revela outras possibilidades para aquilo que na arte se entende por expressão".

Aqui, permitem-se atravessamentos como produção de caminhos mesmo. Estar vivendo como uma aposta política, como afirmação de si. Estar em trânsito, fazer-se no território do vivido. Gerstner relembra-nos: "território aqui é invenção (...) é conquistado". Não há como se desfazer apenas das experiências, do cotidiano, do esforço em ocupar a cidade. É nela e é ela que nos constitui também. Bem como somos nós que a fazemos.

Numa corrente 'transfeminista ${ }^{5}$ ' em franco crescimento quantitativo e qualitativo em todo estado brasileiro, pudemos acessar a "Semana da Visibilidade Trans de Aracaju" desde 2015. São já quatro edições acumuladas na capital sergipana. As reflexões acionadas nesses eventos, portanto, encontraram-se com os questionamentos das um pouco mais que três décadas de vida num corpo anunciado feminino.

\footnotetext{
${ }^{5}$ Para saber mais, sugerimos a leitura de "Transfeminismo: teorias e práticas" (2014) uma obra coletiva liderada pela psicóloga Jaqueline Gomes de Jesus.

${ }^{6}$ Se trata de um evento com duração de alguns dias cujo objetivo mobilizador é, como já anunciado em seu título: visibilizar a existência real, cotidiana, comum das pessoas trans. Ou seja, sair das fantasias de que são seres distantes, guardados em seus armários, que saem à noite para sua função quase hegemônica, da prostituição "compulsória" (como demonstram, inclusive, em conferências desse evento). Deflagrada pela fraterna aliança entre as ONGs "AmoSerTrans" e "UNIDAS" de Sergipe, e, agregando-se coletivos de movimentos sociais Igbt, coletivos de juventude, grupos profissionais sensíveis a causa, coletivos de professores universitários de áreas diversas entre outras(os) interessadas(os) tem produzido efeitos políticos importantes no estado e para além desse território.
} 
O feminismo também já havia se manifestado de várias formas nos últimos anos de trabalho e na vida pessoal. As teorias, na verdade, consubstanciaram-se às reflexões cotidianas proporcionando a percepção e compreensão de um corpo questionador. Perceberse e reconhecer-se mulher é ato político, sim. E, é gesto, ato, compromisso que precisou e precisa se reafirmar corriqueiramente. Analisar as próprias singularidades e, buscar seu lugar no rol das "mulheridades" é um jogo também bastante astuto. Na mesma medida o seriam para o rol de "masculinidades"?

Daí que surgem os entendimentos mais que necessários e urgentes de uma certa militância, quiçá, um ativismo implicado na produção de conhecimento, do conhecimento formal, oficializado por instituições acadêmicas e científicas.

As discussões de "gêneros e (a)sexualidades" seriam intenções de muitos movimentos de mulheres, dos direitos Igbtqia+, de negras e negros, das juventudes, das comunidades e povos tradicionais, quilombolas e indígenas brasileiros. Enfim, as intersecções são valores inalienáveis, urgências irreversíveis. Não se pode abrir mão de destacar, registrar, de afirmar esses lugares, essas origens, essas influências, essa ancestralidade.

Pessoas artistas têm insistido em existir, em sobreviver, e afirmarem-se, inclusive por suas manifestações artísticas, em poéticas contundentes, em fricções estéticas cintilantes, em estardalhaços ético-políticos. Tomaram-nos o fôlego, trouxeram-nos novos ares; reviram e revigoram a nossa cultura. Exemplo dessa qualidade de artista, ou, artivista é a Mc Linn da Quebrada. Mulher trans negra periférica jovem e revolucionária. Ela nos brinda e chama para o fronte afirmando "seu corpo uma campo de batalha", "seu corpo uma ocupação (artística, poética, política)", seu corpo resistência... insurgência.

Ou seja, não haveria como desconsiderar as múltiplas dimensões do ser, do ser humano, do ser humanizado. Ser uma pessoa - que pressuporia uma identificação auto ou heterorreferenciada do seu gênero; ter uma origem étnico-racial, que, no caso do Brasil e nossa miscigenação traz um sem número de significados e significantes; ter uma orientação afetivo-sexual; estar numa determinada faixa etária; ter nascido e/ou ter sido criada(o)/educada(o) numa determinada região ou estado do país, ter tido tal ou qual condições de educação e/ou escolarização; gozar de tais ou quais direitos; herdar ou não tais e quais privilégios sócio-econômico-culturais; ter/estar em tal ou qual condição econômica/financeira/aquisitiva; estar num determinado instante de compreensão da sociedade... Enfim, são marcadores que qualificariam o que viveríamos ou não em nossas existências.

\footnotetext{
${ }^{7}$ A utilização desse termo evitando, intencionalmente, oposição masculinidade/feminilidade, se dá na tomada do movimento "blasFêmea" da Mc Linn da Quebrada e toda provocação do ser mulher, do ser fêmea, da transgressão e da manutenção quando oportuna dos signos já convencionados ao universo do feminino. A saber mais e melhor: https://www. youtube.com/watch?v=ApMrNGJu6Cs\&t=26s e https://www.youtube.com/watch?v=-50hUUG1Ppo .
} 
As artes, portanto, prescindem dessas compreensões, dessas reflexões. Estaríamos lidando com a delimitação "lugar de fala". De onde partiríamos para afirmarmos nossas ideias, nossas pretensões, nossas intencionalidades, nossas "conclusões"? Por isso mesmo, tomamos essa crescente repercussão social das lutas pela visibilização das grandes temáticas "transexualidades", "transgeneridades", "travestilidades". Ou mesmo como alguns grupos e teóricas(os) afirmam "dissidências de gênero". Posto que, conforme vimos construindo, nesses últimos anos, esse campo nos provoca sobre vários prismas.

Um desses prismas diz respeito às noções de "corpo", "corporeidades", "experiências e experimentações corporais"; reafirmamos a aposta central provocada por esse estudo. É bastante curioso o tanto de vieses também possíveis de compreensão e discussão dessa tentativa de recorte. Por exemplo, ao vivenciarmos nosso estar no mundo, estaríamos falando em experiência de performatividade? O que seria, então, performar o gênero no corpo, pelo corpo, corporificar-se?

Correm-se vários riscos, inclusive, a hiper objetificação da pessoa que se insere nesse circuito de afirmação de si e de seu modo de ser ao reduzirmos o conceito à palavra corpo e suas variações. Por isso, aumentamos o cuidado no registro de nossas percepções no que se refere à disputa social afetiva e política desse ser no mundo; disputa do direito a um gênero tantas vezes apontado "pelo social" ${ }^{8 "}$ como "destoando" da noção hegemônica do ser biológico-sexual-moralizado.

A noção de performatividade é ponto caro às artes cênicas. Aliás, durante algum tempo, ela mesma também foi posta como dissidência da hegemônica forma de reconhecer e afirmar as artes cênicas. Muito possivelmente esses descompassos seriam apontados pelas formas normatizadas justo por apontar horizontes mais questionadores do status quo, por ousar destacar as múltiplas modalidades "fora da caixinha" que tanto se pretendem limitar, formatar cartesiana e linearmente. Desta feita, o conceito "performance" derivando "performatividade" e brincando ou mesmo 'ludicizando' com o "estabelecido" padrão de conhecer e aceitar o mundo, como se este fosse uma experiência posta, dada e limitada, é aqui convocada a jogar conosco algumas possibilidades de vivenciar a corporeidade, o corpo, o lugar afetivo ao qual nos colocamos enquanto pessoas cidadãs nesse mundo-palco de encontros existenciais.

Ser alguém seria uma tarefa pronta e irremediável? Estar definida(o) num gênero seria uma experiência estanque? Haveria algo ou qualidades desse algo que seriam aprendidas, construídas, (re)modeladas? Se sim, quais seriam as ferramentas, meios, estratégias, processos que se afirmariam nessa brincadeira? Se não, como explicaríamos ou

\footnotetext{
${ }^{8} \mathrm{O}$ que estamos registrando enquanto social estaria para além do indivíduo, seja seu ambiente familiar, comunitário, escolar, grupos de especialistas em alguma abordagem seja de saúde, das práticas jurídicas, pelo próprio senso comum, ou conjuntura das relações societárias. Das quais pode até ser parte, todavia, em menor escala de interferência ou mesmo produção de norma de regência do convívio.
} 
justificaríamos na história da humanidade, mais recente ou mais longínqua, as contínuas transições e deslocamentos nas/das experiências de performatividade de gênero nas experiências e vivências dos ser homem, ser mulher e todos os seus modos em tantas culturas, localidades, temporalidades e nuances dessas?

No que apontamos, fazemos uma menção à provocação no texto estudado no transcorrer da nossa pesquisa: "A Desnaturalização da Cisgeneridade: impasses e performatividades" (LEAL e MOSTAZO, 2017). A problematização fora feita de maneira bastante perspicaz e, inclusive, com bastante obviedade. De tão óbvio, não nos percebemos inseridas num problema quase matemático; lembremos do jogo da prova dos nove em séries escolares formais iniciais quando, para verificarmos se uma continha aritmética básica estaria correta, faríamos o caminho reverso à questão inicialmente proposta.

Nessa seara seria: se ao reivindicar-se a transgeneridade - diga-se de passagem, é muito mais o apontar de dedo do social para a pessoa que seria transgressora da norma em larga escala do que seu oposto - a pessoa transgênera transicionaria da imposição, a pessoa dita cisgênera não demandaria qualquer desvio da norma. E, na "provinha do noves fora", questiona-se: "toda pessoa cisgênera estaria completamente satisfeita e confortável nesse lugar normatizado associado ao seu corpo biológico-sexual-normatizado pelo "social"? Tal operação não fecha em zero perfeito. Nem todos os homens são os mesmos modelos (de) masculinos tampouco as mulheres sejam os mesmos modelos (de) femininos. Mesmo que as pessoas que estejam alocadas em uma ou outra "categoria: homem / mulher" não tendo, necessariamente, a auto percepção ou consciência objetiva das nuances de "seu grupamento social", é notório num passar de olho rápido pelos corpos nas vias de relações interpessoais que possamos estar inseridas(os).

Enfim, há de se convir que desde o nascimento até o instante último da vida antecedendo a morte que variamos, que nos tornamos quem podemos ser. Invariavelmente somos múltiplas possibilidades de seres humanos em escalas de masculinidades/feminilidades. Assim o sendo, aprenderíamos a ser quem podemos ser? Como se dariam tais processos?

Enquanto estudante futura docente de teatro, proponho enquanto hipótese esta área de saber como uma forte candidata a colaborar com a formação pessoal em seus múltiplos processos de ensino-aprendizagem humanas e sociais. Inclusive, nos "Parâmetros Curriculares Nacionais (PCN) - Arte" (1998) temos que "A arte tem um caráter de conhecimento de si, qual seja, o de busca de sentido, criação, inovação para a vida". Ou seja, a possibilidade de produzir meios de contato consigo por meio da atividade artística e acessar essas construções simbólicas pode ser um caminho viável para a pesquisa das noções de feminino e masculino e suas variações em performatividade e afirmação dos modos de vida transgêneres. 
Retomemos a "educação somática" como grande escola cujas estratégias práticas viabilizariam um contato ao mundo sensível e permeando-se de reflexões filosóficasepistemológicas acumuladas de maneira vivencial e dinâmica. Daí que a Técnica Klauss Vianna estaria contida em nossa aposta de trabalho com pessoas trans e travestis em busca do sensível em si. E, além da especificidade da técnica, teríamos as referências biográficas dos Vianna como aporte complementar nos sustentando. Jussara Miller, pessoa de grande contribuição para a sistematização, memória, registros diversos e repercussão da Técnica Vianna contribui mais uma vez com a seguinte a reflexão do próprio Klauss a seguir o que busco, então, é dar um corpo a essas pessoas, porque elas têm coisas a dizer com seu corpo. Por isso não faço qualquer proposta de movimento que não tenham aplicação na vida diária. Quero que o trabalho seja simples e natural. [...]. O que importa é lançar as sementes no corpo de cada um, abrir espaço na mente e nos músculos. E, esperar que as respostas surjam. Ou não. Todo esse trabalho tem qualquer coisa de paradoxal: falo sobre coisas que devem ser sentidas e não pensadas (KLAUSS VIANNA, 1990, p.131132 apud MILLER, 2007, p.21).

Tudo isso corroborando com nossa proposta metodológica de escrita inauguração de uma reestruturação político-afetiva-intelectual para preparação para ação, bem como com o a percepção ideológica de como manejar com a práxis a ser produzida no encontro mesmo com o público-alvo. Inclusive, alinhando o cerne a vivência e metodologia (quiçá aposta existencial-filosófica dos Vianna) em constante "transição / transformação / transgressão / trânsito / transmutação". Angel Vianna coroa nossa menção ao registrar que "gente é como nuvem, sempre se transforma" (2001 apud MILLER, 2007, p. 51). Portanto, gentes, afeto, intenção, "(...) técnica, como um corpo, respira e se move. Cabe a uma técnica ser suficientemente madura para poder se adaptar às mudanças, às necessidades do homem (ser humano?, grifo nosso), e nunca ao contrário. A técnica é um "meio", e não um "fim" (KLAUSS VIANNA apud MILLER, 2007, p. 52).

\section{ENCAMINHANDO-SE... E, ALGUMA DISCUSSÃO...}

Durante essa pesquisa muitas foram as ocorrências de assassinatos das pessoas a quem dedicamos nossa atenção e interesse em produzirmos um trabalho cuidadoso que una psicologia, teatro, direitos humanos. Muitos foram os ataques sofridos pelas artes e as(os) artistas. Uma certa patrulha hiper moralizante e moralizadora, inclusive no que diz respeito às questões de gêneros e (a)sexualidades que amparam e sustentam a militância e ativismo de grande parte das pessoas trans e travestis. Vide o maldoso ataque a manifestações artísticas em diversos pontos do Brasil associando-as a práticas de pedofilia. 
Muitas vezes, inclusive, assustou-nos ver os artistas de modo geral correrem o risco de perderem seus direitos conquistados há exatos quarenta anos. A saber, a regulamentação das profissões de artista e de técnico em espetáculos de diversões, lei federal 6533 de 1978 sendo foco de procedimentos judiciais para sua invalidação. Ao mesmo tempo, há uma força de resistência, de resiliência muito perspicaz, inclusive, por parte de grupos de pesquisa acadêmicos, de movimentos e coletivos no sentido de produzir formas de organização, de linguagem, modos de vida outros que ressignifiquem o estar no mundo.

Assim parece-nos, sem falsas modéstias, que estamos seguindo um caminho interessante para a construção de saber nas artes que considera a dimensão mais moderna, digamos, de saúde e, que inclui a concepção de que direitos são peças fundamentais na conquista da vida e do viver. Ainda que, não necessariamente sejam fáceis de se conquistar. A Educação Somática contribuiria ainda a esse fluxo de auto conhecimento, de auto reconhecimento, de uma construção de percepção de pertencimento a algo ainda maior que nós mesmas(os).

Construindo o artigo científico pudemos ampliar todas essas noções de uma forma muito inspiradora, motivadora e provocadora.

\section{CONSIDERAÇÕES FINAIS}

Com mais amadurecimento teórico sobre a Técnica Klauss Vianna, compreendendo que ela faz parte de algo maior e, que ela mesma também possui grande dimensão de ser e de aplicabilidade. Com a consolidação dos conhecimentos e reflexões acerca da possibilidade existencial das pessoas trans e travestis e de suas construções ético-políticas enquanto uma grande categoria social. Ficamos com a percepção ainda mais aguçada e com a compreensão de que é um caminho urgente a trilharmos com utilização prática dos conhecimentos acessado e assimilados nesse um ano de pesquisa.

Assim, interessa-nos intensa e ardentemente a continuidade dessas pesquisas, da continuidade da organização desses textos, dessas reflexões, dessa composição de um modo de fazer teatro engajado, implicado no social. Temos muito o que propor, temos muita gente disposta a se experimentar em.

\section{REFERÊNCIAS}

BALTAZAR, Márcia C. (2019) Expressão Corporal: educação somática e política. Revista Repertório. Salvador, ano 21, n. 31, p. 183-198, 2019.1

BALTAZAR, Márcia C. (2017) Plano de Trabalho: Pedagogia do Corpo Criador (ou Teatro Somático). São Cristóvão: UFS. 
GERSTNER, M. (2015) O corpo como território do sensível - aproximações entre arte, educação e clínica. Retirado em agosto de 2017 do http://www.escolaangelvianna.com.br/seminario/anais, homepage.

GREEN, J. (2015) Social somatic theory: issues and applications in dance pedagogy. $\begin{array}{lllll}\text { Retirado em novembro de } & 2017 \text { de }\end{array}$ http://www.fap.pr.gov.br/arquivos/File/RevistaCientificaFAPNumero13Artigo04GreenComplet o.pdf, homepage.

GREEN, J. (2019). Movendo-se para dentro, para fora, através e além das tensões entre experiência e construção social na teoria somática. Revista Repertório. Salvador, ano 22, n. 32, p. 21-43, 2019.1

HINZ, G. P. S. (2015) Investigando a somática: histórias, teorias e possíveis caminhos. Retirado em agosto de 2017 do http://www.escolaangelvianna.com.br/seminario/anais, homepage.

JESUS, Jaqueline Gomes de. Transfeminismo: teorias e práticas. Rio de Janeiro: Metanoia, 2014.

LEAL, D. \& MOTAZO, J. (2017) A desnaturalização da cisgeneridade: impasses e performatividades. Retirado em agosto de 2017 do http://www.ssexbbox.com/2017/04/17/adesnaturalizacao-da-cisgeneridade-impasses-e-performatividades/, homepage.

MILLER, J. (2007) A escuta do corpo: sistematização da técnica Klauss Vianna. São Paulo: Summus Editorial.

NOGUEIRA, S. N. B.; AQUINO, T.A.; CABRAL, E.A. Dossiê: A Geografia dos Corpos das Pessoas Trans. Disponível em: <https://issuu.com/redetransbrasil/docs/redetransbrasil_dossier>. Acesso em: 28 Out. 2017. PORTA, J. A. \& OLIVEIRA, Y. M. (2015) Oficinas de movimento: corpo, clínica e produção de subjetividade. Disponível em: <http://www.escolaangelvianna.com.br/seminario/anais>. Acesso em: Ago. 2017

ROLNIK, S. (?). À sombra da cidadania: alteridade, homem da ética e reinvenção da democracia. Retirado em dezembro de 2017 do http://www.pucsp.br/nucleodesubjetividade/Textos/SUELY/homemetica.pdf, homepage.

SIMBINE, A. et. al. (2015). Pesquisarcom: efeitos de uma oficina de experimentação corporal com pessoas cegas e com baixa visão. Retirado em agosto de 2017 do http://www.escolaangelvianna.com.br/seminario/anais. 